\title{
PENGARUH PROMOSI ONLINE DAN WORD OF MOUTH TERHADAP KEPUTUSAN PEMBELIAN KONSUMEN (STUDI PADA UD. BINTANG SEMBILAN)
}

\author{
Lukmanul Hakim ${ }^{1}$, Bambang Setiyo Pambudi² \\ lukmanu1331@gmail.com, bambang_fe utm@yahoo.co.id \\ Universitas Trunojoyo Madura
}

\begin{abstract}
ABSTRAK
Tujuan dari penelitian ini adalah untuk mengetahui pengaruh promosi online dan word of mouth terhadap keputusan pembelian pada UD Bintang Sembilan. Bintang Sembilan sebagian atau bersamaan. Penelitian ini menggunakan data primer yaitu data yang diperoleh langsung dari konsumen UD. Bintang Sembilan Bintang Sembilan. Sampel menggunakan teknik non-probability sampling yaitu incidental sampling, dengan jumlah sampel 100 responden. Instrumen penelitian menggunakan angket dan dianalisis menggunakan analisis regresi linier berganda. Hasil penelitian ini menunjukkan secara parsial promosi online berpengaruh signifikan terhadap keputusan pembelian dan word of mouth secara parsial berpengaruh signifikan terhadap keputusan pembelian. Secara simultan kedua variabel yaitu promosi online dan word of mouth berpengaruh signifikan terhadap keputusan pembelian

Kata Kunci: Promosi, Word Of Mouth dan Keputusan Pembelian
\end{abstract}

\begin{abstract}
Purpose of this study was to determine the effect of online promotion and word of mouth on purchasing decisions at UD Bintang Sembilan. The Nine Star partially or simultaneously. This study uses primary data, namely data obtained directly from consumers of UD. Bintang Sembilan Nine Star. The population of this research is consumers of UD. Bintang Sembilan using a non-probability sampling technique, namely incidental sampling, with a sample size of 100 respondents. The research instrument used a questionnaire and analyzed using multiple linear regression analysis with t test (partial) and f test (simultaneous).

The results of this study indicate partially online promotion has a significant effect on purchasing decisions and for word of mouth partially has a significant effect on purchasing decisions. Simultaneously, the two variables, namely online promotion and word of mouth, have a significant effect on purchasing decisions.
\end{abstract}

Keywords: Online Promotion, Word Of Mouth and Purchasing Decisions.

\section{PENDAHULUAN}

Home industri merupakan peluang usaha yang mulai bermunculan dalam era sekarang, karena semakin sempitnya lapangan kerja yang tersedia. Industri semacam ini dapat dikelola didalam rumah sehingga dapat dipantau setiap saat. Usaha kecil semacam 
ini dikelola oleh orang-orang yang memiliki hubungan kerabat. Modal yang dibutuhkan usaha ini sedikit dan alat - alat yang digunakan bersifat manual. Usaha kecil mempunyai peran penting dalam pertumbuhan ekonomi suatu negara. Pengembangan usaha kecil di Indonesia merupakan salah satu perioritas dalam pembangunan ekonomi nasional, karena usaha tersebut merupakan tulang punggung sistem ekonomi kerakyatan yang tidak hanya di tunjukkan untuk mengurangi masalah kesenjangan antar golongan dan pendapatan antar pelaku usaha, lebih dari itu yang signifikan dalam mempercepat perubahan struktural. Yakni meningkatnya perekonomian dan ketahanan ekonomi nasional.

Di Kabupaten Sumenep khususnya Kecamatan Manding, mayoritas penduduknya mengolah singkong menjadi kripik. UD. Bintang Sembilan merupakan salah satu home industry di Kecamatan Manding yang memproduksi kripik singkong. Usaha Kripik singkong yang awalnya dikerjakan sendiri namun dengan kegigihan mereka dan tekad meraka sampai saat ini usaha tersebut sudah memiliki banyak karyawan dan mampu bertahan dan berkembang sampai saat ini. Kripik singkong yang dihasilkan memiliki dua varian rasa yaitu original (rasa bawang) dan pedas manis.

Selain UD. Bintang Sembilan, juga terdapat beberapa usaha lain yang juga menghasilkan produk sejenis yang berbahan dari Singkong perusahaan tersebut juga terletak di Kecamatan Manding yang juga menghasilkan produk Kripik Singkong. Hal tersebut merupakan masalah besar bagi perusahaan. perusahaan harus lebih aktif dan kreatif dalam memasarkan atau mempromosikan produknya agar bisa mempertahankan pelanggannya serta memenangkan persaingan pasar, sehingga produknya menjadi pilihan utama bagi konsumen, agar dapat melakukan keputusan pembelian konsumen sehingga usaha bisa terus berkembang. Dalam era global yang ditandai dengan persaingan yang semakin tajam dan kompleks serta tingkat akselerasi yang tinggi, perusahaan dituntut untuk memiliki kemampuan mengembangkan pilihan stratejik sehingga mampu berdaptasi dengan lingkungan dinamis. Melihat kenyataan itu, pasar harus dapat dikelola dengan upaya-upaya yang sistematis untuk mendapatkan keuntungan dari kinerja pasar yang superior (Narver dan Slater, 2011:21).

Upaya perusahaan untuk mempengaruhi konsumen perlu diperhatikan keinginan dari konsumen agar dapat melakukan keputusan pembelian. Dalam pengambilan keputusan merupakan suatu proses kegiatan pembeliaan yang tampak hanyalah satu tahap dari keseluruhan proses pembelian konsumen. Keputusan pembelian harus diperhatikan oleh setiap perusahaan besar maupun perusahaan kecil. Karena hal itu untuk menjaga keberlangsungan perusahaan, oleh karena itu perlu dipelajari seperti apa keinginan dari 
konsumen itu sehingga dapat mempengaruhi keputusan pembelian dari konsumen itu sendiri.

Salah satu upaya yang dilakukan oleh perusahaan agar mecapai tujuan tersebut yaitu dengan strategi promosi online salah satunya adalah menggunakan media sosial. Media sosial online memainkan peran penting dalam pasar konsumen saat ini. Survei menemukan bahwa konsumen menghabiskan rata-rata $22 \%$ waktu online di situs media sosial Nielsen Wire (2010), dan sebagai hasilnya keputusan pembelian mereka sangat berpengaruh. Mengingat pengaruhnya yang semakin besar, bisnis semakin berperan aktif di media sosial online (Kaplan dan Haenlein 2010). Sosial media memungkinkan pengguna untuk melakukan komunikasi dengan jutaan pengguna lainnya. Bagi para pemasar hal ini merupakan suatu potensi dan kesempatan yang sangat besar untuk digunakan sebagai salah satu alat komunikasi pemasaran.

Melalui promosi online penjualan produk dapat lebih terbantu karena memungkinkan proses pemasaran yang lebih efektif, respon yang lebih cepat dan biaya yang lebih murah serta penyebaran informasi yang cepat diharapkan dapat meningkatkan penjualan sehingga UD. Bintang Sembilan dapat mencapai target yang diinginkan, dan juga dapat berkomunikasi dengan konsumen secara interaktif. Komunikasi yang baik dapat mempererat hubungan baik dengan konsumen. Hal tersebut secara tidak langsung akan menjadi kepuasan tersendiri bagi konsumen karena konsumen merasa diperhatikan. Ketika konsumen mendapat kepuasan, maka konsumen akan memberikan testimoni yang positif kemudian akan merekomendasikan kepada orang lain sehingga dapat mempengaruhi keputusan pembelian. Hal ini sesuai dengan penelitian yang dilakukan Kuspriyono (2017) yang menyatakan bahwa promosi online berpengaruh positif terhadap keputusan pembelian.

Selain faktor promosi online tentunya juga terdapat beberapa faktor lain yang juga mempengaruhi keputusan pembelian konsumen seperti faktor word of mouth. Pemilik usaha harus berupaya untuk memberikan dukungan dalam upaya memaksimalkan potensi yang dimiliki untuk memberikan dukungan untuk mempengaruhi kepuatusan pembelian yang dilakukan konsumen. Agar tetap dapat bersaing di pasar, para pelaku usaha dituntut untuk berusaha lebih keras lagi, untuk itu para pelaku usaha perlu melakukan usaha pemasaran yang baik. Salah satu bentuk pemasaran yang dapat dilakukan adalah dengan melakukan Word Of Mouth (WOM). Menurut (Kotler \& Keller, 2012) Kotler \& Keller (2012) Word of Mouth Communication (WOM) atau komunikasi mulut adalah suatu proses komunikasi berupa pemberian rekomendasi baik secara individu maupun 
kelompok terhadap suatu produk atau jasa yang bertujuan untuk memberikan informasi. Menurut Sumardy (2011) Komunikasi dari mulut ke mulut yang berasal dari individu yang pernah menggunakan atau mempunyai pengalaman dengan suatu produk kemudian menyampaikan hal hal yan diketahui tentang produk tersebut kepada individu lain baik yang bersifat positif maupun negatif sehingga dapat mempengaruhi sikap dan perilaku individu dalam pengambilan keputusan. Word of mouth dinilai sangat efektif dalam memperlancar proses pemasaran dan mampu memberikan keuntungan kepada perusahaan.

Terjadinya word of mouth memicu calon konsumen baru untuk melakukan pembelian atas suatu produk yang mereka dengar dari orang lain. Sebelum kansumen akan melakukan pembelian, konsumen tersebut akan mencari informasi mengenai produk dan jasa yang akan di belinya. Informasi tentang produk merupakan salah satu faktor penting yang mempengaruhi konsumen dalam pengambilan keputusan pembelian. Informasi yang didapat oleh konsumen baik positif maupun negatif akan mempengaruhi persepsi konsumen, perlu diperhatikan juga peran konsumen yang pernah membeli produk yang kita jual karena konsumen yang pernah memakai suatu produk dan merasa puas akan produk tersebut, secara otomatis akan menceritakan dan merekomendasikan kepada orang lain sehingga dapat menciptakan keputusan pembelian secara individu. Hal ini sesuai dengan penelitian yang dilakukan Alfian dkk.(2019), dan Kiki joesiana (2018) serta Budi prasetiyo dan Taupik hidayat (2019) yang menyatakan bahwa word of mouth berengaruh positif terhadap keputusan pembelian konsumen. Oleh karena itu penulis tertarik meneliti dengan tujuan untuk mengetahui pengaruh promosi online dan word of mouth terhadap keputusan pembelian.

\section{METODE PENELITIAN}

Jenis penelitian yang digunakan dalam penelitian ini adalah jenis penelitian explanatory, yaitu penelitian yang menjelaskan hubungan kausal antara variabel-variabel penelitian melalui pengujian hipotesis. Metode Penelitian yang di gunakan adalah metode kuantitatif. Data dikumpulkan dengan metode dokumentasi dan studi pustaka. Pengukuran dalam penelitian ini bersifat kuantitatif yang berfokus pada sisi pengaruh promosi online dan word of mouth terhadap keputusan konsumen pada konsumen UD. Bintang Sembilan.

Penelitian ini dilaksanakan dengan menggunakan penarikan sampel secara nonprobabilitiy sampling, yaitu suatu metode pemilihan ukuran sampel di mana setiap 
anggota populasi mempunyai peluang yang tidak sama untuk dipilih menjadi anggota sampel. Teknik yang digunakan adalah purposive sampling, yaitu teknik penentuan sampel berdasarkan kriteria responden dimana responden harus berusia $\geq 17$ tahun dan merupakan konsumen UD Bintang sembilan. Penentuan jumlah sampel pada penelitian ini mengacu pada perhitungan sampel yang dikemukakan oleh Roscoe dalam Sugiyono (2014) dengan beberapa ketentuan. Jumlah responden pada penelitian ini berjumlah 100.

Variabel-variabel yang digunakan dalam penelitian ini, terdiri dari variabel independin yaitu promosi online (X1) dan word of mouth (X2), dan variabel dependen yaitu keputusan pembelian (Y). Dimana indicator dari masing-masing variable meliputi:

- Promosi Online (X1), faktor-faktor yang mempengaruhi seseorang terhadap promosi online Campbell and Wright (2008), yaitu: Personal Relevance, Online Interactivity, Message, Brand Familiarity.

- Word of mouth (X2), indikator word Of mouth (Babin, Barry, 2016) adalah sebagai berikut : Membicarakan, Merekomendasikan, Mendorong.

- Keputusan pembelian (Y), factor yang mempengaruhi pengambilan keputusan pembelian (Tjiptono, 2015) adalah: Identifikasi Kebutuhan, Evaluasi Alternatif, Evaluasi Pasca Pembelian.

\section{HASIL DAN PEMBAHASAN}

\section{Uji Validitas}

Tabel 1

Hasil Uji Validitas

\begin{tabular}{|c|c|c|c|c}
\hline Variabel & Pernyataan & Sig & $\begin{array}{c}\text { Batas } \\
\text { Sig. }\end{array}$ & Ket \\
\hline \multirow{4}{*}{$\begin{array}{c}\text { Promosi } \\
\text { Online }\end{array}$} & $X .1 .1$ & 0,000 & 0,05 & VALID \\
\cline { 2 - 5 } & $X .1 .2$ & 0,000 & 0,05 & VALID \\
\cline { 2 - 5 } & $X .1 .3$ & 0,000 & 0,05 & VALID \\
\cline { 2 - 5 } $\begin{array}{c}\text { Word } \\
\text { Of } \\
\text { Mouth }\end{array}$ & $X .1 .4$ & 0,000 & 0,05 & VALID \\
\cline { 2 - 5 } & $X .2 .1$ & 0,000 & 0,05 & VALID \\
\hline \multirow{3}{*}{$\begin{array}{c}\text { Keputusan } \\
\text { Pembelian } \\
(Y)\end{array}$} & $X .2 .3$ & 0,000 & 0,05 & VALID \\
\cline { 2 - 5 } & $Y .1$ & 0,000 & 0,05 & VALID \\
\cline { 2 - 5 } & $Y .2$ & 0,000 & 0,05 & VALID \\
\cline { 2 - 5 } & $Y .3$ & 0,000 & 0,05 & VALID \\
\cline { 2 - 5 } & $Y .5$ & 0,000 & 0,05 & VALID \\
\hline
\end{tabular}

Hasil Uji Validitas dengan menggunakan SPSS dari pernyataan Variabel Promosi Online (X1), Word Of Mouth (X2) dan Keputusan embelian (Y) pada instrumen menunjukkan bahwa nilai signifikan 0,000 tidak melebihi batas signifikan 0,05. Berdasarkan uji validitas menunjukkan bahwa semua item pernyataan dinyatakan valid 
dan dapat dijadikan sebagai instrumen penelitian.

\section{Uji Reabilitas}

Tabel 2

Hasi Uji Reabilitas

\begin{tabular}{|c|l|c|c|c|}
\hline NO & Variabel & $\begin{array}{c}\text { Cronbach's } \\
\text { Alpha }\end{array}$ & $\begin{array}{c}\text { Batas } \\
\text { Cronbach's } \\
\text { Alpha }\end{array}$ & Ket \\
\hline 1 & $\begin{array}{l}\text { Promosi } \\
\text { Online }\end{array}$ & 0,717 & 0,70 & Reliabel \\
\hline 2 & $\begin{array}{l}\text { Word Of } \\
\text { Mouth }\end{array}$ & 0,942 & 0,70 & Reliabel \\
\hline 3 & $\begin{array}{l}\text { Keputusan } \\
\text { Pembelian }\end{array}$ & 0,767 & 0,70 & Reliabel \\
\hline
\end{tabular}

Dari seluruh variabel promosi online (X1), word of mouth (X2), dan keputusan pembelian (Y) dapat dinyatakan reliable, dikarenakan nilai Cronbach's Alpha yang dihasilkan dari perhitungan mendapatkan nilai lebih tinggi dari kriteria reabilitas yakni lebih dari 0,70 .

\section{Uji Asumsi Klasik Uji Normalitas}

Tabel 3

\section{Hasil Uji Normalitas}

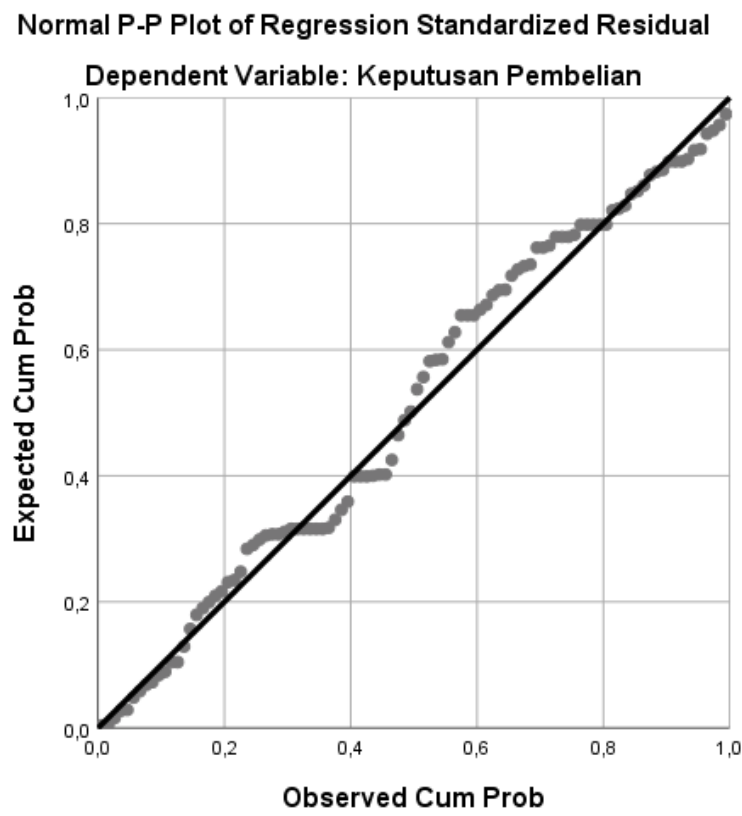

Berdasarkan Normal Probability Plot diatas, terlihat bahwa titik - titik menyebar dan berhimpitan di sekitar garis diagonal dan penyebarannya mengikuti garis diagonal tersebut. Hal ini menunjukkan bahwa data dalam penelitian ini berdistribusi normal. 


\section{Uji Multikolinieritas}

\section{Tabel 4}

\section{Hasil Uji Multikolinieritas}

\begin{tabular}{|l|l|l|l|}
\hline \multirow{2}{*}{ Variabel } & \multicolumn{2}{|c|}{$\begin{array}{c}\text { Colininearity } \\
\text { Statistik }\end{array}$} & \multirow{2}{*}{ Keterangan } \\
\cline { 2 - 3 } & Toleran & VIF & Ketas Dari \\
\hline $\begin{array}{l}\text { Promosi } \\
\text { Onlin X1 }\end{array}$ & 0,461 & 2,170 & $\begin{array}{l}\text { Bebajala } \\
\text { Gejal }\end{array}$ \\
\hline $\begin{array}{l}\text { Word Of } \\
\text { Mouth } \\
\text { X2 }\end{array}$ & 0,461 & 2,170 & $\begin{array}{l}\text { Bebas Dari } \\
\text { Gejala }\end{array}$ \\
\hline
\end{tabular}

Berdasarkan tabel diatas menunjukkan bahwa semua variabel promosi online (X1) dan word of mouth (X2) memiliki nilai Tolerance $>0,10$ dan nilai VIF $<10$ sehingga dapat disimpulkan tidak terjadi gejala atau bebas multikolinieritas.

\section{Uji Heterokedastisitas}

\section{Tabel 5}

\section{Hasil Uji Heterokedastisitas}

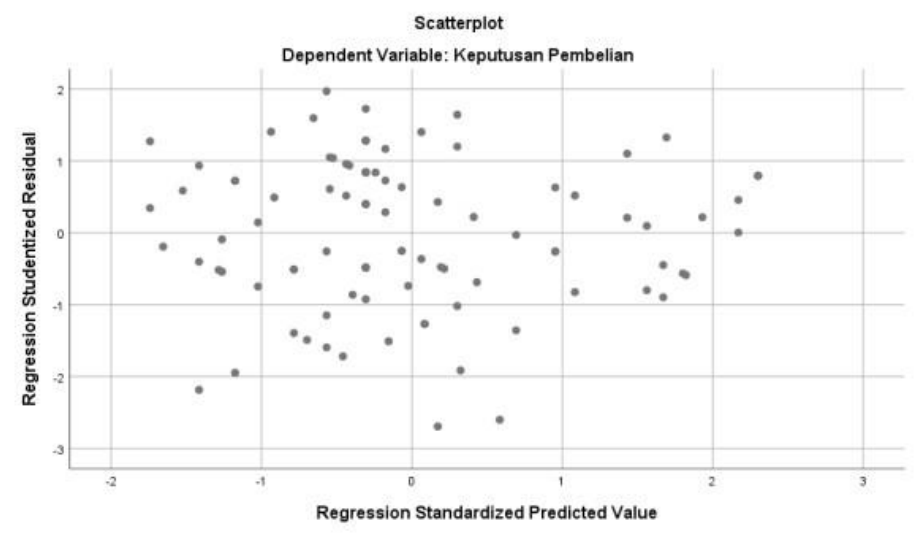

Berdasarkan gambar diatas menunjukkan bahwa titik - titik menyebar secara acak atau tidak beraturan dan menyebar di atas dan dibawah angka nol pada sumbu Y serta tidak membentuk suatu pola tertentu. Dengan demikian dapat disimpulkan bahwa tidak terjadi hetroskedastisitas pada model regresi.

\section{Analisis Regresi Linier Berganda}

$\mathrm{Y}=9,931+0,473 \mathrm{X} 1+0,258 \mathrm{X} 2$

Keterangan:

Y: Keputusan Pembelian

$\mathrm{X} 1$ : Promosi Online

X2: Word Of Mouth 
Pada persamaan regresi diatas, maka dapat di jelaskan bahwa:

1. Nilai Konstanta (a) sebasar 9,931 yang artinya jika seluruh variabel konstan, maka keputusan pembelian bernilai positif.

2. Berdasarkan model persamaan regresi linier berganda dapat dilihat bahwa koefisien dari promosi online (X1) bernilai positif sebesar 0,473. Artinya jika promosi online ditingkatkan sebesar satu kesatuan maka keputusan pembelian meningkat 0,473.

3. Berdasarkan model persamaan regresi linier berganda dapat dilihat bahwa koefisien dari word of mouth (X2) bernilai positif sebesar 0,258. Artinya jika word of mouth ditingkatkan sebesar satu kesatuan maka keputusan pembelian meningkat 0,258.

\section{Uji Hipotesis Uji Parsial (Uji t)}

Tabel 6

Hasil Uji t

\begin{tabular}{|c|c|c|c|}
\hline Model & $\mathbf{T}$ & Sig. & \multirow{2}{*}{ Keterangan } \\
\hline (Constant) & 7,018 & 0,000 & \\
\hline $\begin{array}{c}\text { PROMOSI } \\
\text { ONLINE }\end{array}$ & 3,668 & 0,000 & Diterima \\
\hline $\begin{array}{c}\text { WORD OF } \\
\text { MOUTH }\end{array}$ & 2,604 & 0,011 & Diterima \\
\hline
\end{tabular}

Berdasarkan tabel masing masing variabel bebas dalam penelitian ini adalah sebagai berikut:

1. Promosi Online (X1), nilai t-hitung adalah 3,668>t-tabel yaitu 1,9847 dengan tingkat signifikansi 0,000 lebih kecil dari 0,05. Menunjukkan promosi online berpengaruh signifikan terhadap keputusan pembelian. H1 Diterima: Promosi online berpengaruh signifikan terhadap Keputusan Pembelian

2. Word Of Mouth (X2). t-hitung adalah sebesar 2,604 >t-tabel yaitu 1,9847 dengan signifikansi 0,011 lebih kecil dari 0,05. Menunjukkan Word Of Mouth berpengaruh signifikan terhadap keputusan pembelian. H2 Diterima: Word Of Mouth berpengaruh signifikan terhadap Keputusan Pembelian. 


\section{Uji Simultan (Uji F)}

\section{Tabel 7}

Hasil Uji F

\begin{tabular}{|c|c|c|c|c|c|c|}
\hline \multicolumn{7}{|c|}{ ANOVA $^{a}$} \\
\hline \multicolumn{2}{|c|}{ Model } & $\begin{array}{l}\text { Sum of } \\
\text { Squares }\end{array}$ & Df & $\begin{array}{l}\text { Mean } \\
\text { Square }\end{array}$ & $\mathrm{F}$ & Sig. \\
\hline \multirow{3}{*}{1} & Regression & 386,584 & 2 & 193,292 & 37,170 &, $000^{b}$ \\
\hline & Residual & 504,416 & 97 & 5,200 & & \\
\hline & Total & 891,000 & 99 & & & \\
\hline \multicolumn{7}{|c|}{ a. Dependent Variable: Keputusan Pembelian } \\
\hline \multicolumn{7}{|c|}{ b. Predictors: (Constant), Word Of Mout, Promosi Online } \\
\hline
\end{tabular}

Nilai f-hitung $>$ t-tabel dengan tingkat signifikansi 0,000 lebih kecil dari 0,05. Menunjukkan promosi online dan word of mouth/secara bersama-sama berpengaruh signifikan terhadap keputusan pembelian. H3 Diterima: Promosi online dan word of mouth secara bersama-sama berpengaruh signifikan terhadap keputusan pembelian.

\section{Koefisien determinasi}

\section{Tabel 8}

Hasil Koefisien determinasi

\begin{tabular}{|c|c|c|c|c|}
\hline \multicolumn{5}{|c|}{ Model Summary ${ }^{b}$} \\
\hline Model & $\mathrm{R}$ & $\begin{array}{c}\mathrm{R} \\
\text { Square }\end{array}$ & $\begin{array}{c}\text { Adjusted } \\
\text { R } \\
\text { Square }\end{array}$ & $\begin{array}{l}\text { Std. Error of } \\
\text { the Estimate }\end{array}$ \\
\hline 1 & $659^{a}$ &, 434 & ,422 & 2,280 \\
\hline \multicolumn{5}{|c|}{$\begin{array}{l}\text { a. Predictors: (Constant), WORD OF MOUTH, } \\
\text { PROMOSI ONLINE }\end{array}$} \\
\hline \multicolumn{5}{|c|}{ b. Dependent Variable: KEPUTUSAN PEMBELIAN } \\
\hline
\end{tabular}

\section{PEMBAHASAN}

Analisis sudah dilakukan dalam penelitian ini tentang promosi online dan word of mouth terhadap keputusan pembelian. Unit analisis dari penelitan adalah kripik singkong UD. Bintang Sembilan terletak di kecamatan manding kabupaten Sumenep. Penelitian dilakukan dengan uji instrumen data berupa uji validitas dan uji reliabilitas, uji ini digunakan untuk mengetahui valid atau reabelnya instrumen indikator dari variabel.

Berdasarkan analisis hipotesis secara parsial dengan uji t dan simultan dengan uji- f. Terdapat tiga hipotesis yang di jelaskan sebagai berikut:

1. Pengaruh Signifikan Promosi Online(X1) Terhadap Keputusan Pembelian (Y). Uji hipotesis diketahui bahwa secara parsial promosi online berpengaruh signifikan 
terhadap keputusan pembelian konsumen. Hasil uji-t menyatakan variabel promosi online memiliki nilai t-hitung sebesar 3,668 dengan signifikansi 0,000. t-hitung $(3,668)>$ t-tabel yaitu $(1,660)$ dengan signifikansi 0,000 lebih kecil dari 0,05, Maka variabel promosi online (X1) berpengaruh signifikan terhadap keputusan pembelian (Y). Penelitian ini sesuai dengan penelitian sebelumnya Taat Kuspriyono (2017) menyatakan promosi online berpengaruh signifikan terhadap keputusan pembelian konsumen.

2. Pengaruh Signifikan word of mouth (X2) Terhadap Keputusan Pembelian (Y). Hasil uji hipotesis secara parsial word of mouth berpengaruh signifikan terhadap keputusan pembelian konsumen. Dilihat hasil uji-t menyatakan variabel promosi online memiliki nilai t-hitung sebesar 2,604 dengan signifikansi 0,011. t-hitung $(2,604)>t$ tabel yaitu $(1,660)$ dengan signifikansi 0,011 lebih kecil dari 0,05, maka variabel word of mouth (X2) berpengaruh signifikan terhadap keputusan pembelian (Y). Sejalan penelitian Novita Alfian dan Sengguruh Nilowardono (2019) menyatakan word of mouth berpengaruh signifikan terhadap keputusan pembelian konsumen. Juga penelitian Bagas Aji Pamungkas Siti Zuhroh (2016) word of mouth berpengaruh positif dan signifikan terhadap keputusan pembelian.

Pengaruh Signifinan promosi online (X1) dan word of mouth (X2) secara simultan terhadap keputusan pembelian (Y). Hasil uji hipotesis, secara simultan promosi online dan word of mouth berpengaruh signifikan terhadap keputusan pembelian. Dengan nilai f-hitung>t-tabel dengan signifikansi 0,000 lebih kecil dari 0,05. Menunjukkan promosi online dan word of mouth secara bersama sama berpengaruh signifikan terhadap keputusan pembelian.

\section{SIMPULAN DAN REKOMENDASI}

Berdasarkan dari hasil penelitian dan pembahasan yang telah dilakukan, maka dapat diambil kesimpulan sebagai berikut: Promosi online berpengaruh signifikan terhadap keputusan pembelian konsumen UD. Bintang Sembilan dengan nilai pengaruh sebesar 3,668 dan nilai signifikan $0,000<0,05$. Word of mouth berpengaruh signifikan terhadap keputusan pembelian konsumen UD. Bintang Sembilan dengan nilai pengaruh 2,604 dan nilai signifikan $0,011<0,05$. Promosi online dan word of mouth secara simultan berpengaruh signifikan terhadap keputusan pembelian konsumen UD. Bintang Sembilan dengan nilai pengaruh 37,170 dan nilai signifikan $0,000<0,05$. 


\section{DAFTAR PUSTAKA}

Taat Kuspriyono. (2017). Pengaruh Promosi Online dan Kemasan Terhadap Keputusan Pembelian Kosmetik Merek Sariayu Martha Tilaar . Perspektif. Vol. XV, No. 2.

Rosida dan Intisari Haryanti. (2020), Pengaruh Promosi Online dan Persepsi Harga Terhadap Keputusan Pembelian (Studi Kasus Pada Nithalian Collection Bima). Journal of business and ecomnomics researh. Vol.1, No.2

Erna Susilawati dan Rani Puspita Dhaniawaty. (2020). Pengaruh Ict Dan Promosi Online Terhadap Keputusan Pembelian (Studi Kasus Pada Mahasiswa Prodi Sistem Informasi Unikom Pengguna Online Shop). Majalah ilmiah UNIKOM. Vol.17, No.1

Sugiyono. (2013). Metode Penelitian Kuantitatif Kualitatif R\&D. Bandung: Peneribit Alfabeta.

Sugiyono. (2009). Metode Penelitian Bisnis (Pendekatan Kuantitatif, Kualitatif, dan R\&D). Bandung. Penerbit Alfabeta.

Narbuko, Cholid, Achmadi, H. Abu. (2015). Metodologi Penelitian. Jakarta: PT Bumi Aksara.

Sumarwan, Ujang, Fachrodji, Achmad, Nursal, Adman, Nugroho, Arissetyanto, Nurzal, Erry Ricardo, Setadi, Ign. Anung, Suhayono, Alamsyah, Zeffry. (2014). Pemasaran Strategic: Perspective Value-Based Marketing. Bogor: IPB Press.

Tjiptono, Fandy. (2015). Strategi Pemasaran. Edisi 4. Yogyakarta: penerbit CV. ANDI OFFSET.

Wijayanti, Titik, (2012.) Managing Marketing Plan (Teori \& Aplikasi). Jakarta: PT Elex Media Komputindo.

Alma, Bukhari. (2009). Manajemen Pemasaran dan Pemasaran Jasa. Bandung: Alfabeta.

Simon Hudson \& Karen Thal. (2013). The Impact of Social Media on the Consumer Decision Process: Implications for Tourism Marketing. Journal of Travel \& Tourism Marketing

Bagas Aji Pamungkas \& Siti Zuhroh. (2016). Pengaruh promosi di media sosial dan word of mouth terhadap keputusan pembelian (studi kasus pada kedai bontacos, jombang). Jurnal komunikasi. Vol. X, No. 02

Andrew Tjenghar Widjaja. (2016). Pengaruh Word Of Mouth Dan Electronic Word Of Mouth Terhadap Purchase Intention: Sebuah Studi Kasus Mengenai Perilaku Konsumen Terhadap Jasa Ojek Online Gojek. Jurnal Bisnis dan Manajemen. Vol.53, No.12.

Kiki Joesyiana. (2018). Pengaruh Word Of Mouth Terhadap Keputusan Pembelian Konsumen Pada Media Online Shop Shopee Di Pekanbaru. Valuta. Vol. 4, No.1.

Ghozali, Imam. (2013). Aplikasi Analisis Multivariate dengan Program SPSS. Edisi ketujuh. Semarang: Badan Penerbit Universitas Diponegoro.

Ghozali, Imam. (2018). Aplikasi Analisis Multivariate Dengan Program IBM SPSS 25. Semarang: Universitas Diponegoro.

Pribadi, W. (2010). 16 Cara Efektif Mendatangkan Pelanggan Lewat Internet: Mempromosikan Bisnis dan Menjaring Pasar Lebih Luas. Jakarta: Bukuné. 